\title{
Nucleated Red Blood Cells as a Marker of Acute and Chronic Fetal Hypoxia in a Rat Model
}

Victoria K. Minior, M.D. ${ }^{1}$, Brian Levine, M.D. ${ }^{2}$, Asaf Ferber, M.D. ${ }^{1}$, Seth Guller, Ph.D. ${ }^{3}$, and Michael Y. Divon, M.D. ${ }^{*}$

${ }^{\prime}$ Department of Obstetrics \& Gynecology, Lenox Hill Hospital, New York, New York, USA; ${ }^{2}$ Colorado Center for Reproductive Medicine, New York, New York, USA; and ${ }^{3}$ Department of Obstetrics $\varepsilon^{\circ}$ Gynecology, Tale University, New Haven, Connecticut, USA

\section{ABSTRACT}

Objective: To examine the relationship between duration of fetal hypoxia, nucleated red blood cell (NRBC) count, and fetal growth.

Methods: Pregnant rats were exposed to a severe hypoxia $\left(9.5 \%-10 \% \mathrm{O}_{2}\right)$ for varying time intervals $(2,6$, $12,24,48$, and 120 hours; $n=4$ for each time interval) immediately prior to delivery at term. Normoxic controls were exposed to room air $\left(21 \% \mathrm{O}_{2}\right)$ and matched for all other study variables $(n=4$ rats for each time interval). Pups were delivered via hysterotomy while maintaining exposure gas concentrations. Blood gas analysis and NRBC counts were performed, and fetal body and liver weights were recorded. Student's $t$ test and simple regression were used for statistical analysis.

\footnotetext{
Abbreviations: ICC, intraclass correlation coefficient; NRBC, nucleated red blood cell; WBC, white blood cell. Citation: Minior VK, Levine B, Ferber A, Guller S, Divon MY. Nucleated Red Blood Cells as a Marker of Acute and Chronic Fetal Hypoxia in a Rat Model. Rambam Maimonides Med J 2017;8 (2):eo025. doi:10.5041/RMMJ.10302

Copyright: (C) 2017 Minior et al. This is an open-access article. All its content, except where otherwise noted, is distributed under the terms of the Creative Commons Attribution License (http://creativecommons.org/licenses/by/3.0), which permits unrestricted use, distribution, and reproduction in any medium, provided the original work is properly cited.
}

Disclosure of funding: This work was funded by the ACOG/Ortho-McNeil Pharmaceutical Academic Training Fellowship.

Conflict of interest: No potential conflict of interest relevant to this article was reported.

* To whom correspondence should be addressed. E-mail: mdivon@northwell.edu 
Results: As the duration of hypoxia increased, fetal weight, liver weight, blood bicarbonate, and base excess levels decreased significantly; concomitantly, NRBC counts increased. This increase in NRBCs became statistically significant after 24 hours of exposure. After 48 hours of hypoxia there was a 2.5-fold rise in NRBC count, and after 120 hours of hypoxia there was a 4.5 -fold rise in NRBC count over control levels. After 12 or more hours of hypoxia, fetal body weights were significantly reduced; 120 hours of hypoxia resulted in a 35\% reduction in fetal body weight, a $34 \%$ reduction in fetal liver weight, and $356 \%$ increase in NRBC count.

Conclusion: In a pregnant rat model, chronic maternal hypoxia ( $\geq 24$ hours) results in a significant increase in fetal NRBC counts as well as reduced fetal body weight and organ growth.

KEY WORDS: Fetal growth restriction, fetal hypoxia, nucleated red blood cells

\section{INTRODUCTION}

The presence of elevated levels of nucleated red blood cells (NRBCs) in the peripheral blood of newborns has been traditionally attributed to "asphyxial conditions."1-3 Increased numbers of these cells have been demonstrated in association with acidemia at birth 4,5 and conditions associated with "placental insufficiency" such as fetal growth restriction ${ }^{6-9}$ as well as "intrapartum fetal distress." 10,11 Furthermore, elevated NRBCs have been noted in the newborns of mothers who smoke cigarettes and mothers exposed to excessive air pollution. ${ }^{12,13}$ A direct correlation between decreasing umbilical artery $\mathrm{pH}$ values and NRBC elevation has been noted in the term human fetus at birth.4,5 Similar findings were reported by Soothill et al. studied umbilical cord blood samples attained through cordocentesis from growthrestricted fetuses and demonstrated that the severity of both fetal hypoxemia and fetal acidemia directly correlated with the degree of NRBC elevation. ${ }^{14}$

Human newborns with elevated levels of NRBCs at birth have been shown to suffer a significant increase in both short-term morbidity and mortality and long-term disability. Neonatal complications such as severe respiratory distress, circulatory instability, 7,8 necrotizing enterocolitis, ${ }^{15}$ retinopathy of prematurity, ${ }^{16}$ hypoxic-ischemic encephalopathy, ${ }^{17}$ early-onset neonatal seizures, ${ }^{18}$ prolonged neonatal intensive care unit stay, and neonatal demise ${ }^{10}$ have been reported in association with elevated NRBCs at birth. In addition, significant associations between elevated NRBCs at birth and lifelong complications such as developmental delay ${ }^{17}$ and cerebral palsy $1,19,20$ have been described.

Several authors have speculated that fetal NRBC counts represent a useful marker of chronic intrauterine hypoxia resulting in neurologic injury.1,4,20
Although this marker may have significant potential utility in the medico-legal setting, it seems premature to make this suggestion without scientific documentation of cause and effect. ${ }^{18}$ In fact, to date, the effect of duration of fetal hypoxia on elevation of NRBCs has not been adequately studied. Because of the inability to perform a controlled investigation of the effect of hypoxia on NRBC counts in the human fetus, a pregnant rat model was used in the present study to examine the dose-response effect of acute and chronic fetal hypoxia on fetal blood gas parameters, NRBC count, and birth weight.

\section{MATERIAL AND METHODS}

\section{Animals}

This investigation was approved by the New York University Institutional Animal Care and Use Committee, and all animal care was in strict accordance with National Institutes of Health guidelines. Young adult, nulliparous, Sprague-Dawley rats were purchased from Charles River Laboratories (Raleigh, NC, USA) and were housed in the Division of Laboratory Animal Research facility at the New York University Medical Center. Rats were individually maintained in polycarbonate cages in an environmentally controlled vivarium under a 12-hour-light12-hour-dark cycle. They received a standard laboratory rodent diet. Free access to food and water was provided throughout the experiment. To ensure accurate gestational age dating of pregnancy, rats were mated at our facility. Male and female rats were housed together overnight and mating was confirmed by the presence of a vaginal plug the following morning (day o of gestation).

\section{Experimental Design}

Pregnant rats were randomly allocated to exposure type (hypoxia or control groups) and duration (2, 6, 
$12,24,48$, or 120 hours). Four pregnant rats were included in each group, for each exposure duration. Thus, a total of 48 rats were studied. Pregnant rats in their polycarbonate cages were placed in a specially designed, normobaric, Plexiglas chamber $(15 \times 13 \times 22.5$ inches; $38.1 \times 33 \times 57.1 \mathrm{~cm})$ for the designated exposure preceding delivery. Delivery by hysterotomy occurred on day 21 of gestation (term) for all rats. While study rats were in the chamber, a severely hypoxic environment was created by titrating compressed air and nitrogen to produce the desired oxygen concentration of $9.5 \%-10 \%$. Previous investigators have shown that fetal wastage occurs when the inspired fraction of oxygen falls below 9.5\%. ${ }^{21}$ Carbon dioxide, humidity, and ammonia were eliminated from the chamber by maintaining continuous flow of air through the chamber at a rate of $1.0 \mathrm{~L} /$ minute. Dual stage cylinder regulators (TW Smith, Brooklyn, NY, USA) connected to the gas tanks controlled the flow of gas into a bench top flow meter/mixer-proportioner (Matheson Tri-gas, Montgomeryville, PA, USA) positioned between the Plexiglas chamber and the gas tanks. Prior to initiation of a hypoxic exposure, the oxygen concentration in the Plexiglas chamber was gradually lowered to $10 \%$ via $1.5 \mathrm{~L} /$ minute compressed nitrogen infusion over 1 hour. Control rats were exposed to $21 \%$ oxygen (room air) and matched for all other study variables. Oxygen concentration was continuously monitored by an oxygen analyzer (Hudson RCI, Temecula, CA, USA).

At the completion of the exposure period, rats were immediately placed in an isoflurane chamber and anesthetized. During the period of anesthesia, the original exposure gas concentrations were maintained. Anesthesia was maintained throughout the surgery using a rodent nose cone anesthesia machine with $2.5 \%$ isoflurane. Once adequate anesthesia was achieved, laparotomy was performed and the first uterine horn encountered was exteriorized. An incision was made in the uterine horn opposite the placental insertion site to expose each pup, with the lowermost pup sampled first. Arterial blood gas measurements as well as blood smears were immediately collected from the first six pups occupying the base of the uterine horn and extending cephalad on one side. Blood gases were sampled using the technique of Lueder et al., ${ }^{22}$ where the fetal axillary artery was isolated and severed, and blood was collected into a capillary tube. Throughout this time, the placental circulation remained intact. Blood gas analysis was performed using a Radiometer 700 (Radiometer Medical ApS, Brønshøj, Denmark) series blood gas analyzer on $55-\mu \mathrm{L}$ samples. Subsequently, the mother rat was euthanized with a lethal dose of pentobarbital. Pup weights and location within the uterine horn were documented, and pups were euthanized with a lethal injection of pentobarbital. Subsequently, the fetal liver was dissected and weighed.

\section{Nucleated Red Blood Cell Counts}

Peripheral blood smears were stained with Wright stain. Nucleated red blood cell (NRBC) counts were obtained with the use of a manual cell counter per 100 white blood cells (WBCs) by two independent observers blinded to both exposure type and duration. Nucleated red blood cell counts were obtained for the first six pups delivered, extending from the lowermost to mid uterine horn from each pregnancy. The mean NRBC count for each pregnancy was then used in the data analysis.

\section{Data Analysis}

Statistical analysis was performed using Statview (version 5.0, SAS technologies) and SPSS (version 13.0). Statistical analysis included Student's $t$ test and simple regression where appropriate. Statistical comparisons were made between mean values for each pregnancy for each group unless otherwise specified. For blood gas analysis, only the first blood gas attained was used for statistical comparisons for each pregnancy because results obtained from subsequent pups had an increased potential to be influenced by the physiologic effects of inhaled maternal anesthesia. $P<0.05$ was considered statistically significant.

To assess repeatability of NRBC counts, the intraclass correlation coefficient (ICC) was calculated using the estimates of within- and betweenobserver variability obtained from a two-way mixed effects analysis of variance model. The ICC assesses the agreement of quantitative measurements in terms of consistency and conformity. The ICC ranges from 0 to 1 , where 1 demonstrates perfect reliability and a value of o indicates no repeatability of the measurement. The ICC is commonly interpreted as follows: ICC $<0.4$ indicates poor repeatability; $0.4<$ ICC $<0.75$ indicates fair to good repeatability; and ICC $>0.75$ indicates good to excellent repeatability. ${ }^{23}$ 


\section{RESULTS}

All pups delivered were viable $(n=669)$. There were no spontaneous preterm or term deliveries. Two of the four gestations exposed to 48 hours of hypoxia were associated with meconium staining of amniotic fluid in multiple sacs. The mean number of pups delivered per gestation was $14 \pm 2( \pm \mathrm{SD})$. The number of pups per gestation was not significantly different between hypoxic and control rats at any time point.

\section{Fetal Blood Gas Values}

Maternal exposure to $9.5 \%-10 \%$ oxygen resulted in abnormal blood gas parameters in all hypoxia study groups. Study pups had significantly lower base excess (Figure 1A) and blood bicarbonate levels (Figure 1B) at all time points when compared to control pups. In addition, significantly higher blood lactate levels (consistent with metabolic acidosis) were also noted at $6,24,48$, and 120 hour time points in the hypoxia group as compared to controls (Figure 1C).

\section{Nucleated Red Blood Cell Counts}

Maternal exposure to a severely hypoxic environment resulted in progressive elevations in fetal NRBC counts relative to controls. Statistically significant differences were noted between control and hypoxic gestations at 24, 48, and 120 hours (Table 1 , Figure 2). After 48 hours of hypoxia, there was a $143 \%$ rise in NRBC count over control values $(1388 \pm$ 98 versus $572 \pm 214 \mathrm{NRBC} / 100 \mathrm{WBC}, P=0.0005)$. After 120 hours of hypoxia, there was a $356 \%$ increase in NRBC count over control levels $(1743 \pm 180$ versus $382 \pm 67 \mathrm{NRBC} / 100 \mathrm{WBC}, P=0.0004)$. A wide range in the NRBC count was noted in study and control rats at all time points (Table 1). However, at 48 hours, $88 \%$ of pups in the hypoxia group had an individual NRBC count above the normal range for
A
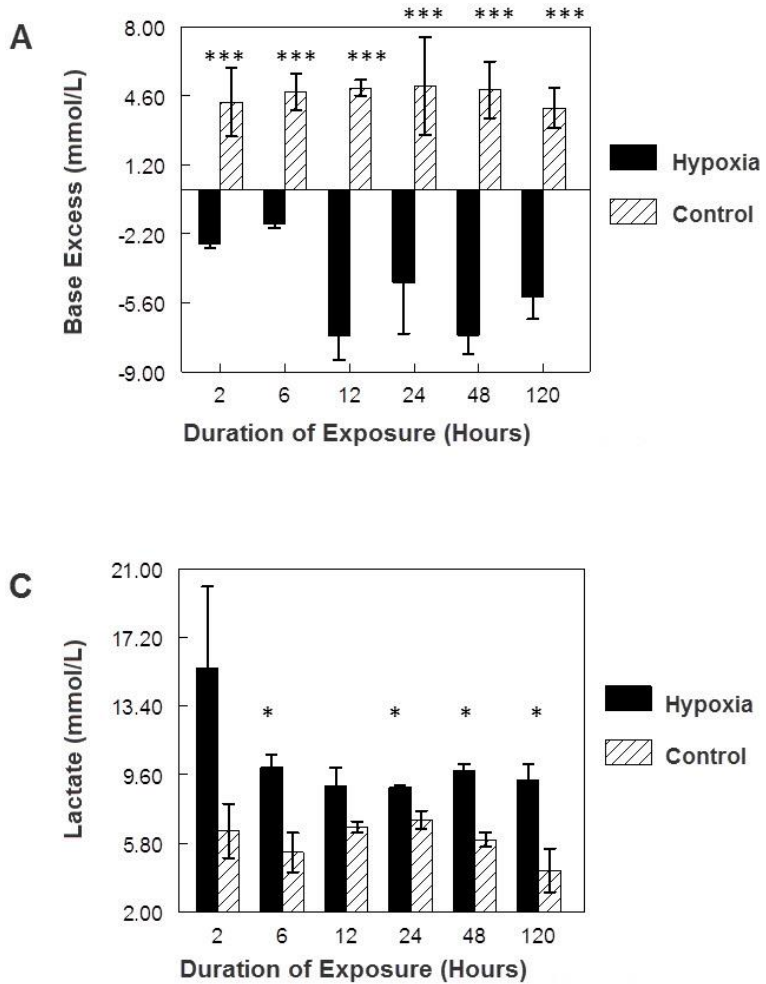

B

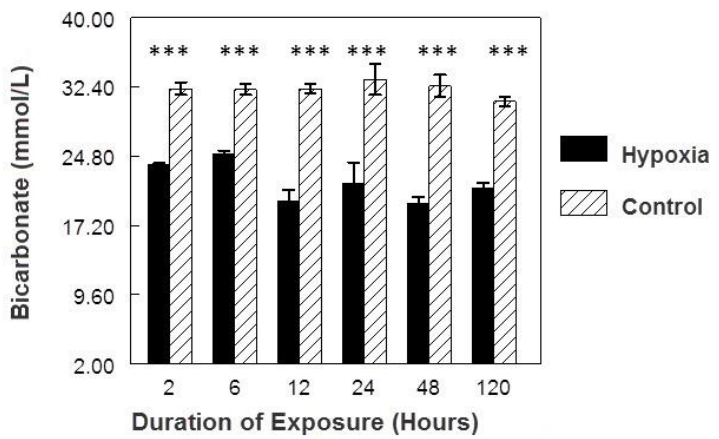

Figure 1. The Effect of Maternal Exposure to 10\% Oxygen on Fetal Blood Gas Parameters.

Rats exposed to hypoxia are represented by the dark bars, control rats are represented by the hatched bars, and error bars represent standard error of the mean. (A) Exposure duration versus base excess ${ }^{* * *} P<0.001$ for all comparisons). (B) Exposure duration versus bicarbonate $\left({ }^{* * *} P<0.001\right.$ for all comparisons). (C) Exposure duration versus lactate $\left({ }^{*} P<0.05\right)$. 


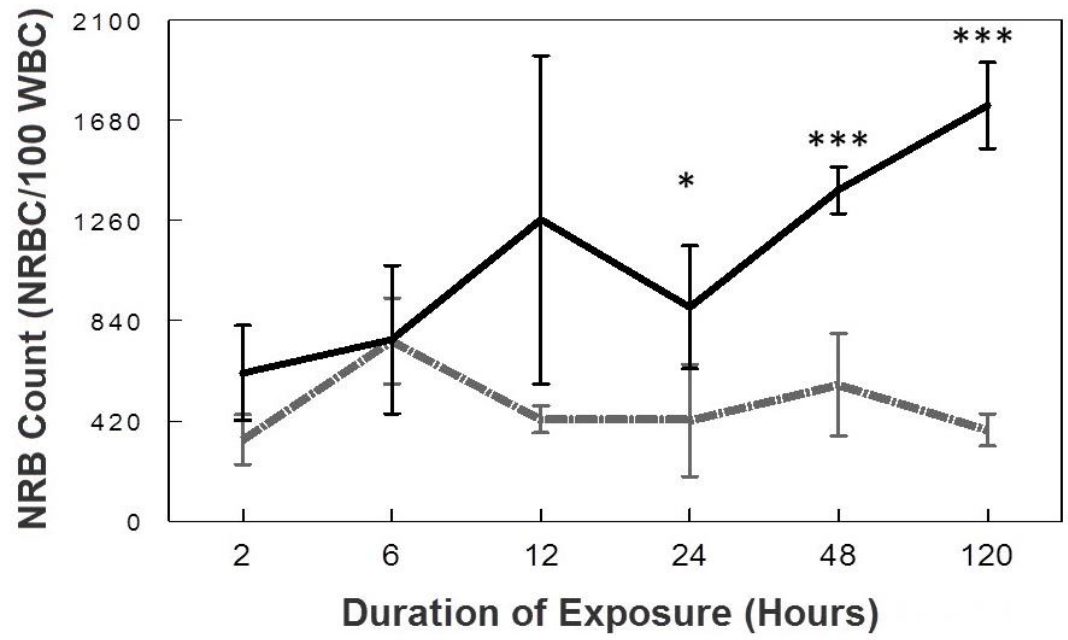

Figure 2. The Effect of Exposure Duration on Fetal NRBC Count.

Control rats are represented by the grey line, study rats are represented by the black line, and error bars represent standard error of the mean. Statistically significant differences were noted between control and hypoxic gestations at 24,48 , and 120 hours $\left({ }^{*} P<0.05,{ }^{* * *} P<0.001\right)$.

controls, and at 120 hours $100 \%$ of pups in the hypoxia group had an individual NRBC count above the normal range for controls.

\section{FETAL BIRTH WEIGHT}

The mean birth weight of control pups at term was $5.47 \pm 0.08 \mathrm{~g}$. In the control group, there was no difference in birth weight with increasing durations of exposure to room air (Figure 3). As expected, prolonged maternal exposure to $9.5 \%-10 \%$ oxygen resulted in fetal growth restriction. As shown in Figure 3, as exposure duration increased, there were progressive decreases in fetal body weight in hypoxic rat pups relative to control rat pups. The difference between control and hypoxic fetal body weights reached statistical significance after 12 hours of hypoxia. After 120 hours of hypoxia, there was a $35 \%$ decrement in fetal weight relative to controls $(3.99 \pm 0.3 \mathrm{~g}$ versus $5.39 \pm 0.09 \mathrm{~g}, P=0.004)$. In addition, there were progressive reductions in fetal liver weight with increasing durations of hypoxia. After 120 hours of hypoxia, there was a 34\% decrement in mean fetal liver weight in study rats relative to controls $(0.23 \pm 0.04 \mathrm{~g}$ versus $0.31 \pm 0.02 \mathrm{~g}$, $P=0.01$ ).

Table 1. With Increasing Duration of Hypoxia, There are Elevations in NRBC Counts over Control Levels.

\begin{tabular}{|c|c|c|c|c|c|}
\hline \multirow{2}{*}{$\begin{array}{l}\text { Exposure } \\
\text { Duration } \\
\text { (hours) }\end{array}$} & \multicolumn{2}{|c|}{$\begin{array}{c}\text { Control } \\
\text { Mean NRBC/100 WBC }\end{array}$} & \multicolumn{2}{|c|}{$\begin{array}{c}\text { Hypoxic } \\
\text { Mean NRBC/100 WBC }\end{array}$} & \multirow{2}{*}{$P$ Value } \\
\hline & $n_{ \pm} \mathrm{SEM}$ & Range & $n \pm S E M$ & Range & \\
\hline 2 & $342 \pm 104$ & $230-473$ & $621 \pm 199$ & $351-774$ & 0.05 \\
\hline 6 & $756 \pm 180$ & $496-901$ & $761 \pm 311$ & 358-1039 & 0.97 \\
\hline 12 & $426 \pm 57$ & $385-510$ & $1264 \pm 688$ & $657-2192$ & 0.05 \\
\hline 24 & $422 \pm 235$ & $125-700$ & $896 \pm 258$ & $542-1138$ & 0.03 \\
\hline 48 & $572 \pm 214$ & $415-874$ & $1388 \pm 98$ & $1304-1523$ & 0.0005 \\
\hline 120 & $382 \pm 67$ & $205-523$ & $1743 \pm 180$ & $1427-2190$ & 0.0004 \\
\hline
\end{tabular}




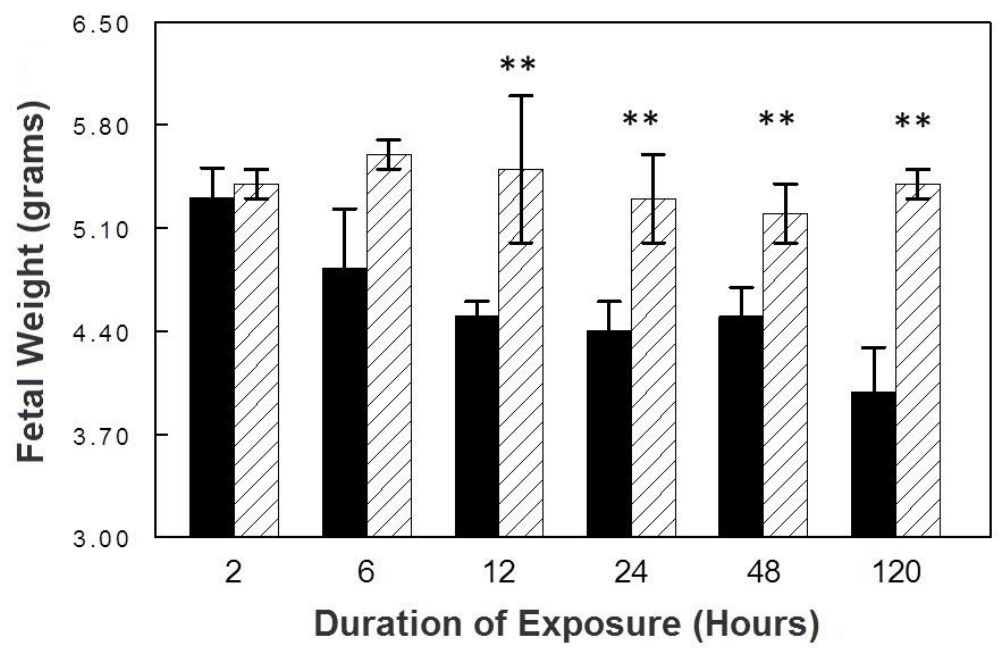

Figure 3. The Effect of Exposure Duration on Fetal Weight.

Hypoxic rats are represented by the black bars, and control rats are represented by the hatched bars $\left({ }^{* *} P<0.01\right)$.

Correlations between NRBC Counts, Fetal Blood Gas Values, and Fetal Birth Weight Regression analysis revealed a significant correlation between NRBC counts and fetal metabolic acidosis as measured by fetal base excess $\left(R^{2}=0.46\right.$, $P<0.0001)$, bicarbonate $\left(R^{2}=0.46, P<0.0001\right)$, and lactate $\left(R^{2}=0.18, P=0.005\right)$, indicating that $\mathrm{NRBC}$ is correlated with hypoxia. Moreover, a significant negative correlation was noted between fetal NRBC counts and fetal weight $\left(R^{2}=0.49, P<0.0001\right)$, with the smallest fetuses having the highest NRBC counts and the largest fetuses having the lowest NRBC counts (Figure 4), consistent with the observation of increase of NRBCs in human fetal growth restric-

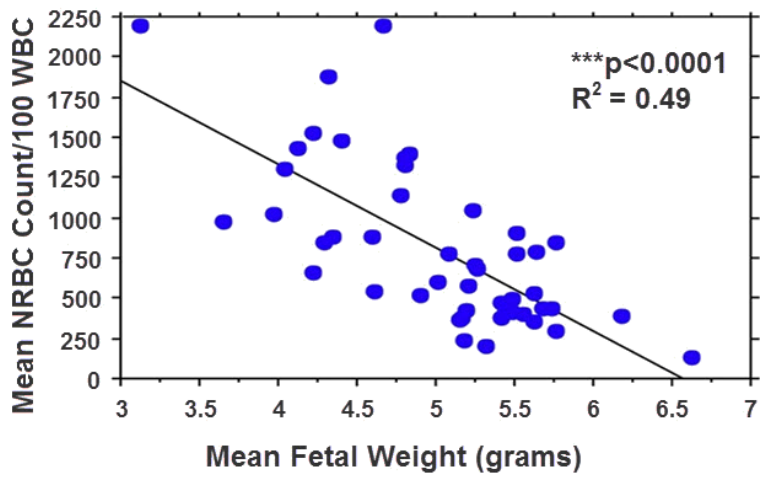

Figure 4. Relationship between NRBC Count and Fetal Weight.

A significant negative correlation was noted between NRBC count and fetal weight $\left(R^{2}=0.49,{ }^{* * *} P<0.0001\right)$. tion. ${ }^{14}$ In addition, simple regression analysis revealed a significant correlation between fetal body weight and the degree of metabolic acidosis as measured by fetal base excess $\left(R^{2}=0.5, P<0.0001\right)$, bicarbonate $\left(R^{2}=0.54, P<0.0001\right)$, and lactate $\left(R^{2}=\right.$ $0.22, P=0.002)$.

Statistical evaluation of within-observer reliability revealed intraclass correlation coefficients of 0.95 (95\% CI $0.678-0.993, P=0.001)$ and 0.98 (95\% CI $0.88-0.998, P<0.0005)$. The ICC for interobserver variability was 0.8 (95\% CI $0.540-0.904$, $P<0.0005)$. These results indicate good agreement within and between observers.

\section{DISCUSSION}

This study demonstrates that, in the term rat fetus, increasing durations of fetal hypoxia result in significant and progressive elevations of NRBCs simultaneous with reductions in fetal body and organ growth. The degree of NRBC count elevation was related to the duration of intrauterine hypoxia. A statistically significant difference in NRBC count in study animals over controls was detected after 24 hours of hypoxia.

As normal human pregnancy advances, the number of circulating erythroblasts or NRBCs decreases exponentially, reaching relatively low levels by $26-28$ weeks' gestation. ${ }^{24}$ At this time, bone cavities become more functional, and a transition occurs from splenic and hepatic erythropoiesis, to medullary erythropoiesis. Prior to 
medullary erythropoiesis, erythroblasts freely circulate in the peripheral blood. As bone marrow erythropoiesis increases, erythroblasts become confined to the medullary parenchyma. ${ }^{25}$ In a normal human newborn delivered at term, there are very few nucleated erythrocytes in the peripheral blood. The mean number of NRBCs is 8.6 per 100 white blood cells, with a standard deviation of $10.3 .{ }^{26}$

The mechanism by which NRBCs become present in elevated numbers in the peripheral fetal circulation has been a topic of much debate. Animal and human fetuses that are delivered from a lowoxygen intrauterine environment have been noted to have an abundance of NRBCs in their peripheral blood. ${ }^{2,27}$ It is speculated that, in an effort to compensate for the lack of adequate oxygen supply, the mammalian fetus accelerates the erythropoietic process. This results in increased numbers of immature erythroblasts and thereby a potential improvement in fetal oxygen-carrying capacity. Erythropoietin is well known to be the primary hormone mediating erythropoiesis. ${ }^{28,29}$ Its secretion results in an increase in red blood cell mass by stimulating proliferation, differentiation, and maturation of erythroid precursors..$^{30}$ In studies of fetal sheep, Widness et al. found that erythropoietin is elevated in response to intrauterine hypoxia approximately 4-6 hours after initiation of an hypoxic insult. ${ }^{31}$ Similar time responses have been documented by in vivo studies of adult rats. ${ }^{32}$ Increases in the number of circulating NRBCs can also occur as a result of hormone-mediated release of NRBCs from bone marrow stores.33 Erythropoietin has been shown to increase blood flow through bone marrow as well as increasing bone marrow porosity, allowing escape of the relatively large and rigid NRBCs into the peripheral circulation. ${ }^{33-35}$ In cases of long-standing, chronic hypoxia, increased extramedullary hematopoiesis has been demonstrated in animal models and in humans. ${ }^{36,37}$ As NRBCs freely circulate under these conditions, elevated peripheral blood NRBCs would be noted.

Acute elevations in peripheral NRBCs may occur secondary to an interleukin (IL)-mediated response..$^{10}$ Recent in vitro studies have demonstrated that erythroid progenitor differentiation and maturation can be induced by IL- 6 in the absence of added erythropoietin ${ }^{38,39}$ and that IL-6 is markedly increased in response to hypoxia in both in vitro studies and in vivo human studies.40,41
Unfortunately, animal studies regarding the association of NRBCs to fetal hypoxia have been few and inconclusive. Blackwell et al. exposed term pregnant rats to acute 2-hour periods of severe hypoxia and demonstrated that fetal NRBCs became significantly elevated 12-24 hours after the exposure. This transient elevation disappeared 36 hours later. ${ }^{42}$ Despite differences in study design, our results are consistent with the observations of Blackwell et al. in that we noted significant elevations in NRBC count at $\geq 24$ hours after initiation of the exposure. However, our results lie in direct contrast to those of Ravishankar et al. who exposed pregnant term rats to 120 hours of severe hypoxia and concluded that chronic hypoxia did not result in significant elevations of NRBCs in the fetal circulation. ${ }^{27}$ These authors did, however, show that fetal NRBCs were significantly elevated following exposure to chronic hypoxia combined with nitric oxide inhibition, sufficient to produce fetal growth restriction. ${ }^{27}$ Unlike the results presented by Ravishankar et al., our results demonstrate a large and significant increase in NRBCs following 120 hours of continuous maternal exposure to severe hypoxia. Neither the Ravishankar et al. nor the Blackwell et al. studies were designed specifically to evaluate the impact of duration of fetal hypoxia on NRBC counts. This is particularly relevant as a multitude of human and animal studies have suggested that chronic fetal hypoxia has a profound impact on neurologic outcome. Our results indicate that 24 hours of continuous exposure to severe hypoxia is sufficient to result in a significant elevation in fetal NRBCs.

Our study has several limitations. It is highly unlikely that the rat's hematopoietic system is essentially identical to that of the human. In fact, recent studies suggest that in the rat the shift to medullary hematopoiesis is completed several weeks to months after birth, rather than during gestation, as in the human fetus. ${ }^{6}$ In addition, the physiologic mechanisms that result in hypoxia in the human fetus are obviously quite different than the maternal exposure used in our model. Because of these differences, it is difficult to state whether or not our conclusions would be applicable to the human fetus. It is, however, interesting to note that our results are consistent with the observations made by Korst et al. and Phelan et al. who concluded that the highest NRBC counts are found in human fetuses with a 
prolonged and persistent (from admission to delivery) non-reactive fetal heart rate pattern. ${ }^{1,20}$ Our data support the assertion of previous investigators that extremely elevated NRBC counts in the term human newborn may be secondary to prolonged periods of hypoxia. ${ }^{1,10}$ In addition, our conclusion that hypoxic exposure of less than 24 hours did not result in a significant elevation of fetal NRBCs is somewhat questionable. As stated in Table 1 , the differences between study and control fetuses were not statistically meaningful at exposures times of less than 24 hours. However, with $P$ values of 0.05 (at 2 and 12 hours of exposure) it is possible that a larger study would conclude that short-term exposure to hypoxia is also associated with elevation of NRBCs, as has been suggested in some human studies. ${ }^{8}$ Regardless of the exact $P$ value, our data support suggestions by previous investigators that acute hypoxic events are not likely to result in extreme elevations in NRBC counts over baseline levels. ${ }^{1}$ Our data also demonstrate a wide variability in NRBC count in the normal (control) individual, a finding occasionally noted in normal term human newborns. ${ }^{26}$

The principal strength of our study is derived from the ability tightly to control an animal model so that the only difference between study and control groups is the exposure to severe hypoxia. For obvious reasons, it would be impossible to control a human study to such an extent. This type of model allows us to eliminate the potential influence of other factors that may affect the NRBC count in the human, such as prematurity or infection/ inflammation. 33,43

Previous retrospective studies of children with cerebral palsy have suggested that the timing of antenatal hypoxic neurologic injury may be determined with use of NRBC counts. ${ }^{6}$ The use of an animal model has allowed us to address this issue and manipulate the intrauterine environment in a way not possible in humans. Our results clearly indicate that in the rat model, fetal NRBCs are significantly elevated following 24 hours of maternal exposure to severe hypoxia.

\section{REFERENCES}

1. Korst LM, Phelan JP, Ahn MO, Martin GI. Nucleated red blood cells: an update on the marker for fetal asphyxia. Am J obstet Gynecol 1996;175:843-6. Crossref
2. Bedrick AD. Nucleated red blood cells and fetal hypoxia: a biologic marker whose 'timing' has come? J Perinatol 2014;34:85-6. Crossref

3. Anderson G. Studies on the nucleated red cell count in the chorionic capillaries and the cord blood of various ages of pregnancy. Am J Obstet Gynecol 1941; 42:1-14. Crossref

4. Blackwell SC, Refuerzo JS, Hassan SS, Wolfe HM, Berry SM, Sorokin Y. Nucleated red blood cell counts in term neonates with umbilical artery $\mathrm{pH}<$ or $=$ 7.00. Am J Perinatol 2001;18:93-8. $\underline{\text { Crossref }}$

5. Hanlon-Lundberg KM, Kirby RS. Nucleated red blood cells as a marker of acidemia in term neonates. Am J Obstet Gynecol 1999;181:196-201. Crossref

6. Redline RW. Elevated circulating fetal nucleated red blood cells and placental pathology in term infants who develop cerebral palsy. Hum Pathol 2008; 9:1378-84. Crossref

7. Minior VK, Shatzkin E, Divon MY. Nucleated red blood cell count in the differentiation of fetuses with pathologic growth restriction from healthy small-forgestational-age fetuses. Am J Obstet Gynecol 2000; 182:1107-9. Crossref

8. Minior VK, Bernstein PS, Divon MY. Nucleated red blood cells in growth-restricted fetuses: associations with short-term neonatal outcome. Fetal Diagn Ther 2000;15:165-9. $\underline{\text { Crossref }}$

9. Bernstein PS, Minior VK, Divon MY. Neonatal nucleated red blood cell counts in small-for-gestational age fetuses with abnormal umbilical artery Doppler studies. Am J Obstet Gynecol 1997;177:1079-84. Crossref

10. Ferber A, Grassi A, Akyol D, O'Reilly-Green C, Divon MY. The association of fetal heart rate patterns with nucleated red blood cell counts at birth. Am J Obstet Gynecol 2003;188:1228-30. $\underline{\text { Crossref }}$

11. Masoudi Z, Akbarzadeh M, Vaziri F, Zare N, Ramzi $M$. The effects of decreasing maternal anxiety on fetal oxygenation and nucleated red blood cells count in the cord blood. Iran J Pediatr 2014;24:285-92.

12. Dollberg S, Fainaru O, Mimouni FB, Shenhav M, Lessing JB, Kupferminc M. Effect of passive smoking in pregnancy on neonatal nucleated red blood cells. Pediatrics 2000;106:E34.

13. Ziaei S, Nouri K, Kazemnejad A. Effects of carbon monoxide air pollution in pregnancy on neonatal nucleated red blood cells. Paediatr Perinat Epidemiol 2005;19:27-30. $\underline{\text { Crossref }}$

14. Soothill PW, Nicolaides KH, Campbell S. Prenatal asphyxia, hyperlacticaemia, hypoglycaemia, and 
erythroblastosis in growth retarded fetuses. Br Med J (Clin Res Ed) 1987;294:1051-3. Crossref

15. Mandel D, Lubetzky R, Mimouni FB, et al. Nucleated red blood cells in preterm infants who have necrotizing enterocolitis. J Pediatr 2004;144:653-5. Crossref

16. Lubetzky R, Stolovitch C, Dollberg S, Mimouni FB, Salomon M, Mandel D. Nucleated red blood cells in preterm infants with retinopathy of prematurity. Pediatrics 2005;116:e619-22. Crossref

17. Buonocore G, Perrone S, Gioia D, et al. Nucleated red blood cell count at birth as an index of perinatal brain damage. Am J Obstet Gynecol 1999;181:1500-5. $\underline{\text { Crossref }}$

18. Blackwell SC, Refuerzo JS, Wolfe HM, et al. The relationship between nucleated red blood cell counts and early-onset neonatal seizures. Am J Obstet Gynecol 2000;182:1452-7. $\underline{\text { Crossref }}$

19. Phelan JP, Ahn MO, Korst LM, Martin GI. Nucleated red blood cells: a marker for fetal asphyxia? Am J Obstet Gynecol 1995;173:1380-4. Crossref

20. Phelan JP, Korst LM, Ahn MO, Martin GI. Neonatal nucleated red blood cell and lymphocyte counts in fetal brain injury. Obstet Gynecol 1998;91:485-9. Crossref

21. Van Geijn HP, Kaylor WM Jr, Nicola KR, Zuspan FP. Induction of severe intrauterine growth retardation in the Sprague-Dawley rat. Am J Obstet Gynecol 1980;137:43-7. Crossref

22. Lueder FL, Kim SB, Buroker CA, Bangalore SA, Ogata ES. Chronic maternal hypoxia retards fetal growth and increases glucose utilization of select fetal tissues in the rat. Metabolism 1995;44:532-7. Crossref

23. Fleiss JL. Design and Analysis of Clinical Experiments. New York, NY: John Wiley \& Sons; 2011.

24. Nicolaides KH, Thilaganathan B, Mibashan RS. Cordocentesis in the investigation of fetal erythropoiesis. Am J Obstet Gynecol 1989;161:1197-200. 당s

25. Lichtman M, Chamberlain J, Santillo P. Factors Thought to Contribute to the Regulation of Egress of Cells from Marrow. In: Silber R, LoBue J, Gordon AS, eds. The Year of Hematology. New York: Plenum; 1978:243.

26. Hanion-Lundberg KM, Kirby RS, Gandhi S, Broekhuizen FF. Nucleated red blood cells in cord blood of singleton term neonates. Am J Obstet Gynecol 1997; 176:1149-54; discussion 1154-6. $\underline{\text { Crossref }}$
27. Ravishankar V, Buhimschi CS, Booth CJ, et al. Fetal nucleated red blood cells in a rat model of intrauterine growth restriction induced by hypoxia and nitric oxide synthase inhibition. Am J Obstet Gynecol 2007;196:482.e1-8. $\underline{\text { Crossref }}$

28. Graber SE, Krantz SB. Erythropoietin and the control of red cell production. Annu Rev Med 1978;29:51-66. Crossref

29. Matoth Y, Zaizov R. Regulation of erythropoiesis in the fetal rat. Isr J Med Sci 1971;7:839-45.

30. Jelkmann W. Erythropoietin: structure, control of production, and function. Physiol Rev 1992;72:44989.

31. Widness JA, Teramo KA, Clemons GK, et al. Temporal response of immunoreactive erythropoietin to acute hypoxemia in fetal sheep. Ped Res 1986; 20:15-19. $\underline{\text { Crossref }}$

32. Jelkmann W, Kurtz A, Bauer C. Extraction of erythropoietin from isolated renal glomeruli of hypoxic rats. Exp Hematol 1983;11:581-8.

33. Hermansen MC. Nucleated red blood cells in the fetus and newborn. Arch Dis Child Fetal Neonatal Ed 2001;84:F211-15. $\underline{\text { Crossref }}$

34. Iversen PO. Blood flow to the haemopoietic bone marrow. Acta Physiol Scand 1997;159:269-76. Crossref

35. Chamberlain JK, Leblond PF, Weed RI. Reduction of adventitial cell cover. An early direct effect of erythropoietin on bone marrow ultrastructure. Blood Cells 1975;1:655.

36. Bozzini CE, Barrio Rendo ME, Devoto FC, Epper CE. Studies on medullary and extramedullary erythropoiesis in the adult mouse. Am J Physiol 1970;219: 724-8.

37. Brannan D. Extramedullary hematopoiesis in anemias. Bull Johns Hopkins Hosp 1927;41:104-35.

38. Sui X, Tsuji K, Tajima S, et al. Erythropoietinindependent erythrocyte production: signals through gp130 and c-kit dramatically promote erythropoiesis from human CD34+ cells. J Exp Med 1996;183:83745. $\underline{\text { Crossref }}$

39. Stachon A, Bolulu O, Holland-Letz T, Krieg M. Association between nucleated red blood cells in blood and the levels of erythropoietin, interleukin 3, interleukin 6, and interleukin 12p70. Shock 2005; 24:34-9. $\underline{\text { Crossref }}$ 
40. Klausen T, Olsen NV, Poulsen TD, Richalet JP, Pedersen BK. Hypoxemia increases serum interleukin-6 in humans. Eur J Appl Physiol Occup Physiol 1997; 76:480-2. $\underline{\text { Crossref }}$

41. Ulich TR, del Castillo J, Yin SM, Egrie JC. The erythropoietic effects of interleukin 6 and erythropoietin in vivo. Exp Hematol 1991;19:29-34.

42. Blackwell SC, Hallak M, Hotra JW, et al. Timing of fetal nucleated red blood cell count elevation in response to acute hypoxia. Biol Neonate 2004; 85:217-20. Crossref

43. Dulay AT, Buhimschi IA, Zhao G, et al. Nucleated red blood cells are a direct response to mediators of inflammation in newborns with early-onset neonatal sepsis. Am J Obstet Gynecol 2008;198:426.e1-9. Crossref 